\title{
Anxiety Visual Analogue Scale
}

National Cancer Institute

\section{Source}

National Cancer Institute. Anxiety Visual Analogue Scale. NCI Thesaurus. Code C141607.

An anxiety scale from 0 to 10 on which the patient marks the current level of anxiety experienced. 